\title{
The Deception Clues in Forensic Contexts: The Lie Detection Psychology
}

\author{
Heena Goswami ${ }^{1^{*}}$, Abhishek Kakker ${ }^{1}$, Niha Ansari ${ }^{2}$, Anand Lodha ${ }^{3}$ and Alok Pandya ${ }^{3^{*}}$ \\ ${ }^{1}$ Division of Science \& Technology, Gujarat National Law University, Gandhinagar, Gujarat, India \\ ${ }^{2}$ Department of Forensic Science, Gujarat University, Ahmedabad, Gujarat, India \\ ${ }^{3}$ Division of Biological \& Life Sciences, School of Arts \& Sciences, Ahmedabad University, Ahmedabad, Gujarat, India
}

“Corresponding authors: Heena Goswami, Division of Science \& Technology, Gujarat National Law University, Gandhinagar, 382007 , Gujarat, India, Tel: 79 23276611; Fax: 79 23276613; E-mail: hgoswami@gnlu.ac.in

Alok Pandya, Division of Biological \& Life Sciences, School of Arts \& Sciences, Ahmedabad University, Ahmedabad, 380009, Gujarat, India, Tel: +919722608272; Email: alokpandya20@gmail.com

Received: June 01, 2016; Accepted: September 29, 2016; Published: October 07, 2016

Copyright: @ 2016 Goswami $\mathrm{H}$, et al. This is an open-access article distributed under the terms of the Creative Commons Attribution License, which permits unrestricted use, distribution, and reproduction in any medium, provided the original author and source are credited.

\begin{abstract}
The psychologist and legal professional have an interest as important study of lie detection which revolves as one of the foremost areas of applied psychology. Indeed, in legal settings, police offices, and attorneys are among those make sure with the responsibility to determine clues which is important to know whether someone is lying or telling the truth in investigations, court trials, border control interviews and intelligence interviews. Therefore, psychologists and practitioners have developed various lie detection tools which cover entire possible range from observing behavior, analyzing speech, and measuring peripheral physiological responses to recording brain activity. This article will bring in the reader to the main lie detection tools and theories that underpinned to date in reference to deception.
\end{abstract}

Keywords: Psychology; Lie detection; Polygraph; Deception; Examination

\section{Introduction}

Evidence plays an essential role to establish a linkage between the suspects, crime, scene of crime and sometimes even the victim. With an aid of set evidences one can even enact the modus operandi. Identification of proper evidence and their further analysis to prove or disprove the facts in court is another crucial challenge. Testimony of victim, suspects, accused, and eyewitness can always be sustained with scientific facts which would avoid any sort of further clarifications or doubts in justice delivery system. Proved facts can even avert the need examination and cross examination of each of them and trim down the number of criminal trials. [1-4]. Varity of methods and techniques like "Agni Pariksha", "Rice Test", "Bird's Eag", "Sward Test" exist with their roots in history and in modern era techniques like Lie detector, Narco test, Brain Fingerprinting etc. is been employed for the testimony [5]. Historic methods were non-scientific which may fall into wrong perceptions which may sometimes lead to incorrect or wrongful interpretations or decisions. However, modern scientific techniques are more reliable as they are based on testified facts and can replace the older techniques for testimony.

Polygraph, also known as Lie Detector is more widely used and famous technique of modern science with the development in the $20^{\text {th }}$ century, intended for the psychophysiological detection of deception. It is also known as a psychophysiological detection of deception (POD) examination. The working principle is based on the attribute changes in the Blood pressure, Respiration and Electrical resistance (Galvanic Skin Responseor-GSA) which can be measured simultaneously [6,7]
The first realistic submission was accomplished by Berkeley Police department who applied polygraph test in law enforcement invented by Dr. John A Larson.

Polygraph test resides on the principle that the fear of recognition and entrapment prompts a person to deceit from the actual fact which escort to a mental excitation which is further tried to conceal by physiological effort, known as "Defense mechanism". In Polygraph test the machine detects, not lies, but arousal of emotions indirectly, only the physiological changes which immediately follow any sudden stress emotion. Polygraph simply indicates various physiological functions (breathing, pulse, blood-pressure, sweating, etc.), as well as any sudden changes in these functions. Such body functions become momentarily disturbed by either physical stimuli or emotional stimuli. Moreover, that the machine does not depend upon lying can be indicated by the fact that it reveals the arousal of emotion even when the person does not answer the crucial questions [8]. These physiological activities or diverged features are associated with provocation in the autonomic nervous system and are recorded using different sensors which collectively are known as polygraph. To measure the respiratory changes corrugated rubber tube is tied around the chest, known as Pneumograph, cardiovascular changes is measured using the Sphygmograph by wrapping it round upper arm. Similarly to measure the changes in the galvanic skin response, electrodes are attached to the palm or fingers of the subjects with a transducer attached to the thumb. This transducer measures the blood volume, reflecting the pulse rate which known as the Plethysmograph.

All the above stated sensors are collectively evaluated to find out presence of emotional stress experienced during the assessment with a specific set of questions asked to subject (Figure 1). 


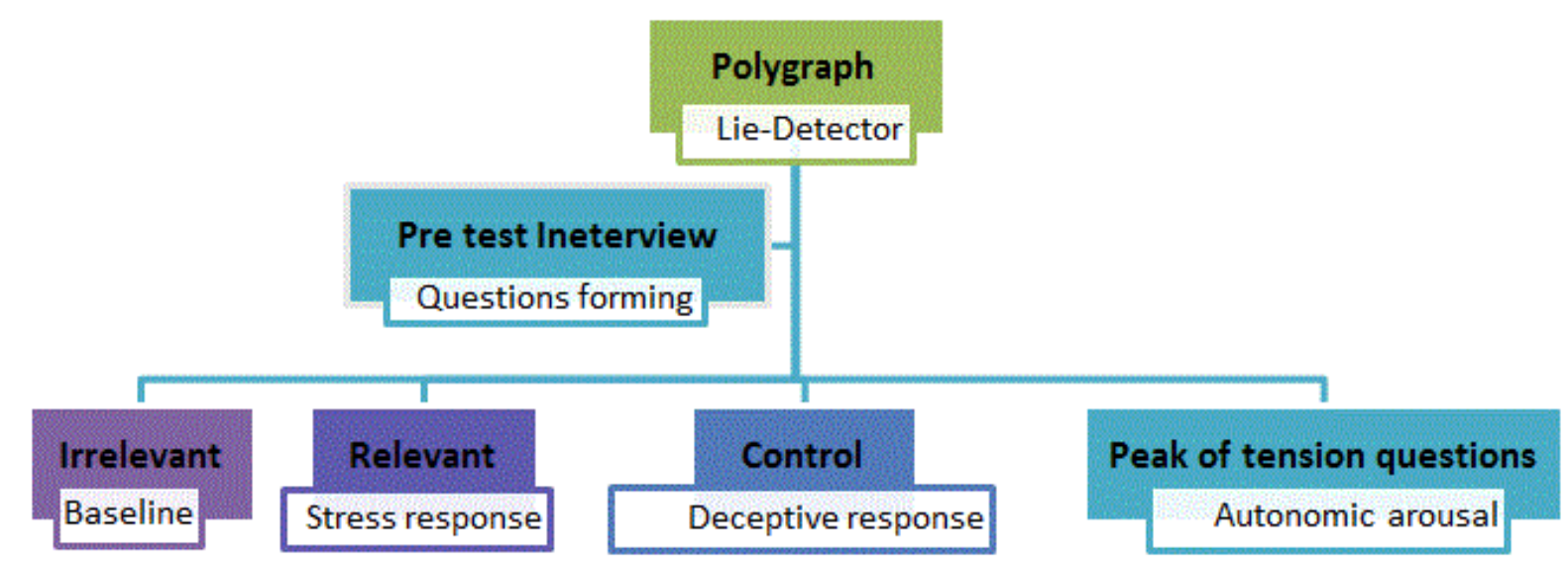

Figure 1: Diagram shows the examination process of victim in polygraph.

These questions are prepared before the assessment by examiner after pretest interview of the subject which enables the examiner to access the subject, formulate the questions and plan the questions pattern. During this interview examiner explains the subject case details, working instrumentation and also take consent of the subject for conducting test. Four different set of questions like irrelevant, relevant, control and peak of tension, are prepared to testify the subject. Here irrelevant questions provide base line of truthfulness while recording the deception response which came from the stressed response from the guilty, of relevant questions. Whereas control questions are asked between relevant and irrelevant questions to evoke a deceptive response to a question. The Control Question Test (CQT, additionally named the Comparison Question Test) thinks about reactions to applicable inquiries with reactions to control questions. Investigating officer figure control questions for which, in their view, disavowals are tricky. The accurate plan of these inquiries will rely on upon the examinee's circum-positions, yet a control question in an examination with respect to a scene of occurrence. In general, this assessment operates under the assumption that irrelevant questions will show baseline physiological responses, guilty examinees will show consistently stronger physiological reactions in response to the relevant question and innocent examinees will show consistently stronger physiological reactions in response to the comparison questions [9]. Recorded response to each questions using polygraph are examined by skilled examiner where by and large, it is up to the examiner(s) to set the cut-off focuses at which a given reaction is demonstrative of misleading, trustworthiness or uncertain; whether to measure all channels and reactions similarly or allocate more weight to a few; and in conclusion whether the general results show blame/duplicity, guiltlessness/genuineness or are just uncertain. Numerical scoring strategies are generally utilized in this progression and ordinarily include the task of negative scores for showed misleading and positive scores for demonstrated trustworthiness to everything (e.g., -5 to +5 ) and including them together into a total score [10]. There are a few modernized scoring frameworks that plan to invalidate the issue of scoring predisposition, yet they have been found to have 'humble exactness' at best [11]. Some endeavour to reproduce the manual scoring process, an illustration being the Computerized Polygraph System. Its present calculation depends on genuine criminal case information gave by US Secret Service [12] and just uses skin conductance abundancy, the plentifulness of increment in the benchmark of the cardiograph, and joined upper and lower breath line length as information $[12,13]$.

There are several computerized scoring systems that aim to nullify the problem of scoring bias, but they have been found to have 'modest accuracy' at best [14-19]. Some attempt to recreate the manual scoring process, an example being the Computerized Polygraph System. Its current algorithm is based on real criminal case data provided by US Secret Service [20] and only uses skin conductance amplitude, the amplitude of increase in the baseline of the cardiograph, and combined upper and lower respiration line length as data.

Examining the subject with a delusional disorder could pass the test false negative if the person believe that he/she was influential by truth where no supplementary category of physiological changes are present. On other hand subject with anxiety, nervousness, anger, sadness, embarrassment, fear and other uncommon medical conditions cause the physiological changes which lead to false positive test tool $[21,22]$. In addition police-induced confessions, interrogation tactics, certain personality traits etc. sometimes can prompt false confessions [23].

To evade such problems it should be taken in to the consideration that the polygraph evidence should be collaboratively used with other evidences.

\section{In Civil Cases, it may be used in:}

- Diagnostic, Therapeutic or interventional \& Rehabilitative (Clinical Psychology)

\section{In Criminal Cases, it may be used in:}

- Investigative (Forensic Psychology)

- Reformation by Reasoning \& Rehabilitation (R\&R) i.e., Neuro Criminology.

Secondly current research and improvements in polygraph test indicates it should be restricted to prove the innocence of the subject rather than to prove his guilt or crime. Moreover, private sectors can address issue like:

- Mental Status Examination

- Competency

- Custody evaluations 
- Disability evaluations

- Detection of deceptions

- Rendering diagnostic opinion regarding the honesty or dishonesty

The control question test may be useful as an investigative aid and tool to induce confessions, it does not pass congregate as a scientifically credible test. This test is based on immature, implausible postulations indicating biased against innocent individuals and also could be beaten simply by artificially augmenting responses to control questions. Therefore, scientists, including members of the Society for Psychophysiological Research, hold negative views about the test who have the requisite background to evaluate the control question test are overwhelmingly skeptical of the claims made by polygraph proponent [24,25].

\section{Summary and Future Prospects}

The quality of polygraph research and investigations has upgraded significantly over the past three-four decades. Polygraph already serves as a viable investigative tool to investigation agencies which provoke the research to address its existing limitations to improve the reliability of the polygraph test. Despite the fact that it may not be feasible to enhance the polygraph to the level where it can genuinely be considered as 'The Lie Detector', it appears to hold the capability of getting to be a standout amongst the best tool with the end goal of helping investigating agencies in the detection of deception. Its utilization for helping the investigative procedure through, for case, differentiates the person on interest, is not very far away.

\section{References}

1. Rastogi P, Kanchan T, Das S, Daya P (2004) The Truth behind Lie Detector. J Indian Acad Forensic Med 30: 161-163.

2. Abrams S, Ogard E (1986) Polygraph surveillance of probationers. Polygraph 15: 174-182.

3. Abrams S, Simmons G (2000) Post-conviction polygraph testing: Then and now. Polygraph 29: 63-67.

4. Ahlmeyer S, Heil P, McKee B, English K (2000) The impact of polygraphy on admissions of victims and offences in adult sexual offenders. Sex Abuse 12: 123-139.

5. Barrick MJ, Mount MK (1991) The Big Five personality dimensions and job performance: A meta-analysis. Pers Psychol 44: 1-26.

6. Cunliffe F, Piazz PB (1980) Criminalistics and Scientific Investigation. New Jersey, Prentice-Hall Inc, USA, pp: 373-385.

7. Vrij A, Verschuere B (2015) Lie Detection in a Forensic Context. Oxford bibliographies, USA.
8. Porter S, Woodworth M, Trust ARB (2000) Truth, Lies, and Videotape: An Investigation of the Ability of Federal Parole Officers to Detect Deception. Law Hum Behav 24: 643-658.

9. Furnham A (2014) The Clues to Deceit: The Psychology of Lie Detection.

10. Sharma BR (2001) Forensic Science in Criminal Investigations and Trials (3rd edn), Delhi, Universal Law Publishing Company Pvt Ltd, India, pp: 17-24.

11. Burack B (1955) Critical Analysis of the Theory, Method, and Limitations of the Lie Detector, A. J Crim Law Criminol 46: 414-426.

12. Kircher JC, Raskin DC (2002) Computer methods for the psychophysiological detection of deception. In: Kleiner $M$ (ed), Handbook of Polygraph Testing. San Diego, Academic Press, USA, pp: 287-326.

13. Synnott J, Dietzel D, Loannou M (2015) A review of the polygraph: history, methodology and current status. Crime Psychol Rev 1: 59-83.

14. Krapohl D, McManus B (1999) An objective method for manually scoring polygraph data. Polygraph 28: 209-222.

15. Dollins A, Krapohl D, Dutton D (2000) A Comparison of computer programs designed to evaluate psychophysiological detection of deception examinations. Psychophysiology 37: S19.

16. Webb K, Chonts CR, Kircher JC, Bernhardt P, Cook AE (2009) Effectiveness of pupil diameter in a probable-lie comparison question test for deception. Legal Criminol Psych 14: 279-292.

17. Nelson R, Handler M, Blalock B, Cushman B (2016) Blind Scoring of Confirmed Federal You-Phase Examinations by Experienced and Inexperienced Examiners: Criterion Validity with the Empirical Scoring System and the Seven-Position Model. Polygraph 45: 22-38.

18. Kassin SM, Drizin SA, Grisso T, Gudjonsson GH, Leo R, et al. (2010) Police-induced confessions: Risk factors and recommendations. Law Hum Behav 34: 3-28.

19. Grubin D (2002) The potential use of polygraph in forensic psychiatry. Crim Behav Ment Health 12: 45-55.

20. Honts CR, Devitt MK, Winbush M, Kircher JC (1996) Mental and physical countermeasures reduce the accuracy of the concealed knowledge test. Psychophysiology 33: 84-92.

21. Gunn J, Gudjonsson GH (1988) Using the psychological stress evaluator in conditions of extreme stress. Psychol Med 18: 235-238.

22. Giddens L, Barron KW, Bl-Craven J, Clark KF, Winter KS (2013) Vocal Indices of Stress: A Review. J Voice 27: 390.e21-390.e29.

23. Harnsberger JD, Hollien H (2016) Assessing Deception by Voice Analysis. Invest Sci J 8: 1-21.

24. Appleby SC, Kassin SM (2016) When self-report trumps science: Effects of confessions, DNA, and prosecutorial theories on perceptions of guilt. Psychol Public Policy Law 22: 127-140.

25. Shakhar GB, Dolev K (1996) Psychophysiological detection through the Guilty Knowledge Technique: Effects of mental countermeasures. J Appl Psychol 81: 273-281. 